\title{
Are State and Provincial Governments Tax Smoothing? Evidence from Panel Data*
}

\author{
MARK C. STRAZICICH \\ The Ohio State University \\ Newark, Ohio
}

\section{Introduction}

The theory of debt examined here is known variously as "efficient taxation over time," "optimal taxation over time," the "equilibrium approach to fiscal policy," or "tax smoothing." Tax smoothing results when an efficient government fixes tax rates today to minimize the costs of taxation over time. Given the long-run constraint of a balanced budget, if the marginal costs of taxation are an increasing function of the amount of resources taxed (i.e., the "tax rate"), then minimization of the total costs of taxation implies that the planned tax rate will be constant over time. Tax rate changes will be unpredictable and the tax rate will behave as a random walk. Efficient governments will not adjust tax rates to accommodate temporary changes in expenditures and revenues. Instead, governments will minimize tax rate changes by "tax smoothing." Smoothing tax rates implies that temporary changes in government spending and output result in deficits and surpluses. Therefore, tax smoothing provides a theory of government debt. The model is primarily due to Barro [1]. The goal of this paper is to contribute to our understanding of government debt. The focus of this paper is on state and provincial debt, or what is generally referred to as "state and local debt."

Nearly every state government in the United States has a balanced budget rule. However, balanced budget rules are not sufficient to rule out tax smoothing, as state governments could build up budget surpluses in good times to smooth budgets over the business cycle. If state governments are smoothing tax rates, then their budget surpluses are endogenous. Contrary to the state governments, provincial governments in Canada have no balanced budget rules. If provincial governments are smoothing tax rates, it could explain the behavior of their budget deficits and surpluses.

As shown by Barro, tax smoothing implies that the (overall) tax rate behaves as a random walk and the tax rate would be a nonstationary time series with a unit root. This study examines the tax smoothing hypothesis in two ways. First, the random walk implication is examined directly by testing the null hypothesis that the tax rate time series has a unit root. Second, if the tax rate behaves as a random walk, then changes in the tax rate should be unpredictable from past information. If past information can predict tax rate changes, this would provide evidence in favor of an alternative hypothesis.

A rejection of tax smoothing suggests that state and provincial tax rates respond to current

*The author gratefully acknowledges helpful comments from Levis Kochin, Paul Evans, and an anonymous referee. 
conditions, rather than seeking to minimize the costs of intertemporal tax distortions. For example, a rejection of tax smoothing by state governments, combined with balanced budget rules, suggests that state governments balance budgets annually in response to current conditions. ${ }^{1}$ This could explain the occurrence of state budget crises during times of slow output growth and/or fast expenditure growth. A rejection of tax smoothing by provincial governments might suggest some sort of political business cycle to explain their sometimes large budget deficits, even on current expenditures.

Empirical testing is undertaken using annual data for fifty states and ten provinces respectively. Tests are performed with panel data, created by pooling data on each state or province. The use of panel data significantly increases the power of the unit root test to reject its null hypothesis. Results clearly reject tax smoothing by state governments, but results cannot reject tax smoothing by provincial governments. Differences in resource mobility is suggested as an explanation for the differences in tax smoothing.

Section II looks at the theory of efficient taxation over time. Section III describes the model. Section IV discusses the tax rate data. Sections V and VI present the empirical tests. Section VII summarizes the results.

\section{Efficient Taxation over Time}

Tax smoothing implies that efficient governments set tax rates today to minimize the cost of intertemporal resource substitution, subject to a long-run balanced budget constraint. Given all available information, the tax rate would be considered as permanent and would not be arbitrarily changed. Only new information about the future path of government spending and output would cause governments to change the tax rate. No prediction could be made of future tax rate changes; therefore, the tax rate would behave as a random walk, and today's tax rate would be the best predictor of future tax rates.

Empirical testing of the tax smoothing hypothesis has focused on federal governments. ${ }^{2} \mathrm{Re}-$ sults of these tests have been mixed. Barro [2;3], Kochin, Benjamin, and Meador [13], and Huang and Lin [11] find general support for tax smoothing by the U.S. federal government. Gupta [10] finds evidence supporting tax smoothing when examining the Canadian federal tax rate. Sahasakul [16], and Bizer and Durlauf [6; 7] reject tax smoothing for the U.S. federal government. Trehan and Walsh [18] reject tax smoothing when examining U.S. federal tax revenues. These tests examine either the time series properties of the tax data, or estimate regression models suggested by tax smoothing. Application of these tests to a single state or provincial government is not recommended. The time series available for a single state or province is too short to get reliable estimates. By examining panels created by pooling data from fifty states or ten provinces, the

1. Some states on a biennial budget cycle need only deal with a budgetary shortfall every two years.

2. One exception has been Horrigan [12]. In a regression based on Barro [1], Horrigan looks at the estimated coefficients for deviation from the values predicted by tax smoothing. Using quarterly U.S. federal debt, Horrigan finds some support for Barro's model. Using combined federal, state and local debt Horrigan finds weaker support. Using only state and local debt, he finds "little confirmation" of Barro's model, and concludes that state and local governments are not tax smoothing. Potential problems with Horrigan's test include the use of time trends to estimate trend real GNP and trend real government expenditures. If trend output and spending are nonstationary, then their regression on time may result in spurious regressions. Horrigan also makes no distinction between current and capital debt. A distinction may be important, as resource mobility encourages state and local governments to finance capital expenditures with debt. 
size of each sample is greatly increased, resulting in more efficient estimation and significantly increased power to reject the null hypothesis.

Benjamin and Kochin $[4 ; 5]$ suggest the ability of efficient governments to smooth tax rates may be restricted at the state and local levels. Mobility of taxable resources may prevent state and local governments from tax smoothing. As temporary deficits and surpluses occur, mobile resources could seek out jurisdictions where the current benefits of government spending exceed the current costs. This would limit the ability of efficient state and local governments to smooth tax rates and could explain the large number of balanced budget rules that exist among these governments in the U.S.

The mobility of taxable resources is likely to be less between provinces in Canada than between states in the U.S. for a number of reasons. First, Canada's provinces are generally larger in area than most states. Second, having two official languages, with French being confined largely to Quebec, and to a lesser extent New Brunswick, mobility would be more costly for large segments of the Canadian population. ${ }^{3}$ Third, many cities in the U.S. are in close proximity to one or more cities in a neighboring state. Neighboring cities among two or more Canadian provinces is rare. All of these examples would make the relative cost of resource mobility greater in Canada than in the U.S. Population mobility estimates support this: the percent of the population changing state or province each year is greater in the U.S. than in Canada. ${ }^{4}$

\section{The Model}

The model defines a government budget identity at period $t$ as follows:

$$
G_{t}+r B_{t-1} \equiv \tau_{t} Y_{t}+B_{t}-B_{t-1}
$$

where $G_{t}$ is real total government expenditures excluding interest on the public debt for state or province $i, r$ is the real rate of interest for state or province $i, B_{t}$ is the real stock of public debt outstanding for state or province $i$ at the end of period $t, Y_{t}$ is the real output of state or province $i$, and $\tau_{t}$ is the "tax rate" of state or province i. $\tau_{t} Y_{t}$ equals the total real tax revenue collected by state or province $i$ in time $t$, or $T_{t}$. Dividing terms in equation (1) by real output of state or province $i$, an intertemporal budget constraint can be derived as follows:

$$
\sum_{j=0}^{\infty}(1+\rho)^{-j} \mathrm{E} g_{t+j}+(1+\rho) b_{t-1}=\sum_{j=0}^{\infty}(1+\rho)^{-j} \mathrm{E} \tau_{t+j}
$$

where $\mathrm{E}$ is the expectation operator, $g_{t} \equiv G_{t} / Y_{t}, \tau_{t} \equiv T_{t} / Y_{t}, b_{t} \equiv B_{t} / Y_{t}$, and $\rho$ is the real interest rate minus the growth rate of real output for state or province $i$, and is assumed to be constant over time.

The model assumes the marginal cost, or marginal excess burden, of tax collection is an increasing function of $\tau_{t}$. Total costs of taxation are assumed to increase quadratically with $\tau_{t}$, and

3. It is also interesting to note that until Canada's constitution in 1982, provinces were legally able to deny employment in certain industries to workers from other provinces. The constitution now prohibits this, except under some limited circumstances.

4. See, for example, U.S. Bureau of the Census [19] and Statistics Canada [17]. 
the marginal excess burden function is assumed to be time invariant. The time path of government spending is assumed to be exogenous. As shown in Barro [1], minimization of the present value of the total cost of taxation over time, subject to the intertemporal budget constraint, implies equality of $\tau_{t}$ over time. Sahasakul shows that after substituting $\mathrm{E} \tau_{t+j}=\tau_{t}$ for all $j \neq 0$ in (2), equation (3) can be derived as follows:

$$
\tau_{t}=\bar{g}_{t}+\rho b_{t-1}
$$

where $\bar{g}_{t}$ is the permanent expenditures to output ratio of state or province $i$ at time $t$, and $\rho b_{t-1}$ equals debt interest payments net of the real output growth rate times the ratio of outstanding real public debt to real output for state or province $i$ at the end of period $t-1 . \bar{g}_{t}$ is equivalent to an annuity value of present and expected future government spending relative to output, and is similar in structure to a measurement of permanent income.

Equation (3) shows that only the ratio of permanent government spending to output, and the stock of previously outstanding government debt relative to output, will determine the tax rate of state or province $i$ at time $t$. Temporary changes in spending or output result in a temporary deficit or surplus, with no change in $\tau_{t}$.

Given all information available today about the future path of spending and output, the tax rate $\tau_{t}$ is expected to remain unchanged. Therefore, today's tax rate is an unbiased predictor of future tax rates. This condition can be described in equation (4) as follows:

$$
\mathrm{E}\left(\tau_{t+j} \mid I_{t}\right)=\tau_{t}
$$

where $I_{t}$ is the information relevant to tax smoothing available to state or province $i$ at time $t$. Equation (4) implies that the tax rate behaves as a random walk. Equation (5) describes the random walk condition as follows:

$$
\tau_{t}=\mu+\tau_{t-1}+\varepsilon_{t} \quad \varepsilon_{t} \sim\left(0, \sigma^{2}\right) \quad \text { and } \quad \mathrm{E}\left(\varepsilon_{t} \varepsilon_{t-j}\right)=0 \quad j \neq 0
$$

where $\mu$ is a constant term or "drift" for state or province $i$, and $\varepsilon_{t}$ is a white noise error term that is independent and identically distributed. Tax smoothing may or may not exhibit a drift in tax rates. With the case of a constant marginal cost function for tax rates over time, tax smoothing implies that $\mu=0$.

The random walk model of equation (5) implies that $\tau_{t}$ is nonstationary with a unit root. A unit root implies that the coefficient on $\tau_{t-1}$ in equation (5) is equal to one. Repeated substitution for $\tau_{t-1}$ into (5) gives equation (6) as follows:

$$
\tau_{t}=\tau_{0}+\mu t+\sum_{j=1}^{t} \varepsilon_{j} .
$$

A nonstationary $\tau_{t}$ implies that innovations in $\varepsilon_{t}$ result in permanent changes in $\tau_{t}$. Therefore, under the null hypothesis of tax smoothing changes in $\tau_{t}$ are permanent, and rejection of a unit root for $\tau_{t}$ rejects tax smoothing. 


\section{Tax Rate Data}

Tests using panel data will be undertaken with annual data for the fifty U.S. states and the ten Canadian provinces over the periods $1963-89$ and 1961-89 respectively. $\tau_{i t}$ is calculated as total tax revenue divided by Gross State Product (GSP) for each state $i$, and total tax revenue divided by Gross Domestic Product (GDP) for each province $i$. Data definitions and sources are shown in the appendix.

Tax revenue for each state government is measured over the fiscal year $(F Y)$, while GSP is measured over the calendar year $(C Y)$. Therefore, tax revenue for each state $i$ will be converted to the calendar year by equation ( 7$)$ as follows:

$$
C Y_{i t}=\phi_{i} F Y_{i t}+\left(1-\phi_{i}\right) F Y_{i t+1}
$$

where $\phi=.5$ for forty-six states, $\phi=.75$ for Alabama and Michigan, $\phi=.25$ for New York, and $\phi=.67$ for Texas. ${ }^{5}$

Some revenue received by state and provincial governments may be considered as nontax revenue. This revenue could occur if governments sell, rent, or lease any assets they own. This type of revenue is not a tax per se since people are paying some rent or fee for the use of a government owned asset. Federal government transfer revenue to the states or provinces is also a type of nontax revenue. There is no reason why tax smoothing should occur for nontax revenue; therefore, to examine the tax smoothing hypothesis more accurately, nontax revenue will be omitted from $\tau_{i t}{ }^{6}$

\section{Unit Root Tests}

Unit root tests in panel data are undertaken on $\tau_{i t}$, the tax rate of state or province $i$ at time $t$. The random walk implication of tax smoothing can be examined by testing the null hypothesis of a unit root in $\tau_{i t}$. Rejection of a unit root rejects tax smoothing.

Levin and Lin [14] describe the asymptotic properties of testing for a unit root in panel data. Their paper extends the work of Dickey and Fuller [8], among others, to panel data. In the case where the disturbances are independent and identically distributed, and no individual-specific fixed effects are present, a unit root in $\tau_{i t}$ causes the $t$-statistic on $\tau_{i t-1}$ to converge to a standard normal distribution. With individual-specific fixed effects a unit root causes the $t$-statistic on $\tau_{i t-1}$ to converge to a non-central normal distribution. Serially correlated disturbances also cause the unit root $t$-statistic to diverge from the standard normal distribution but can be corrected by including lagged values of $\Delta \tau_{i t}$. The asymptotic distribution of the $t$-statistic is not affected by the inclusion of a constant term, time trend, or time-specific fixed effects, or by the values of any individual-specific fixed effects. Levin and Lin provide critical values of the $t$-statistic on $\tau_{i t-1}$ for various finite sample sizes, with and without the presence of individual-specific fixed effects.

The unrestricted unit root test in panel data can be specified in equation (8) as follows:

5. The fiscal year ends June 30 in all but four states. The fiscal year ends September 30 in Alabama and Michigan, March 31 in New York, and August 31 in Texas. Equation (7) is similar to equation (3.1) in Evans and Karras [9]. (1)-(3)

6. To be consistent with the model, nontax revenue must also be subtracted from government spending in equations 
Table I. State Tax Rate Unit Root Tests in Panel Data: 1964-1989

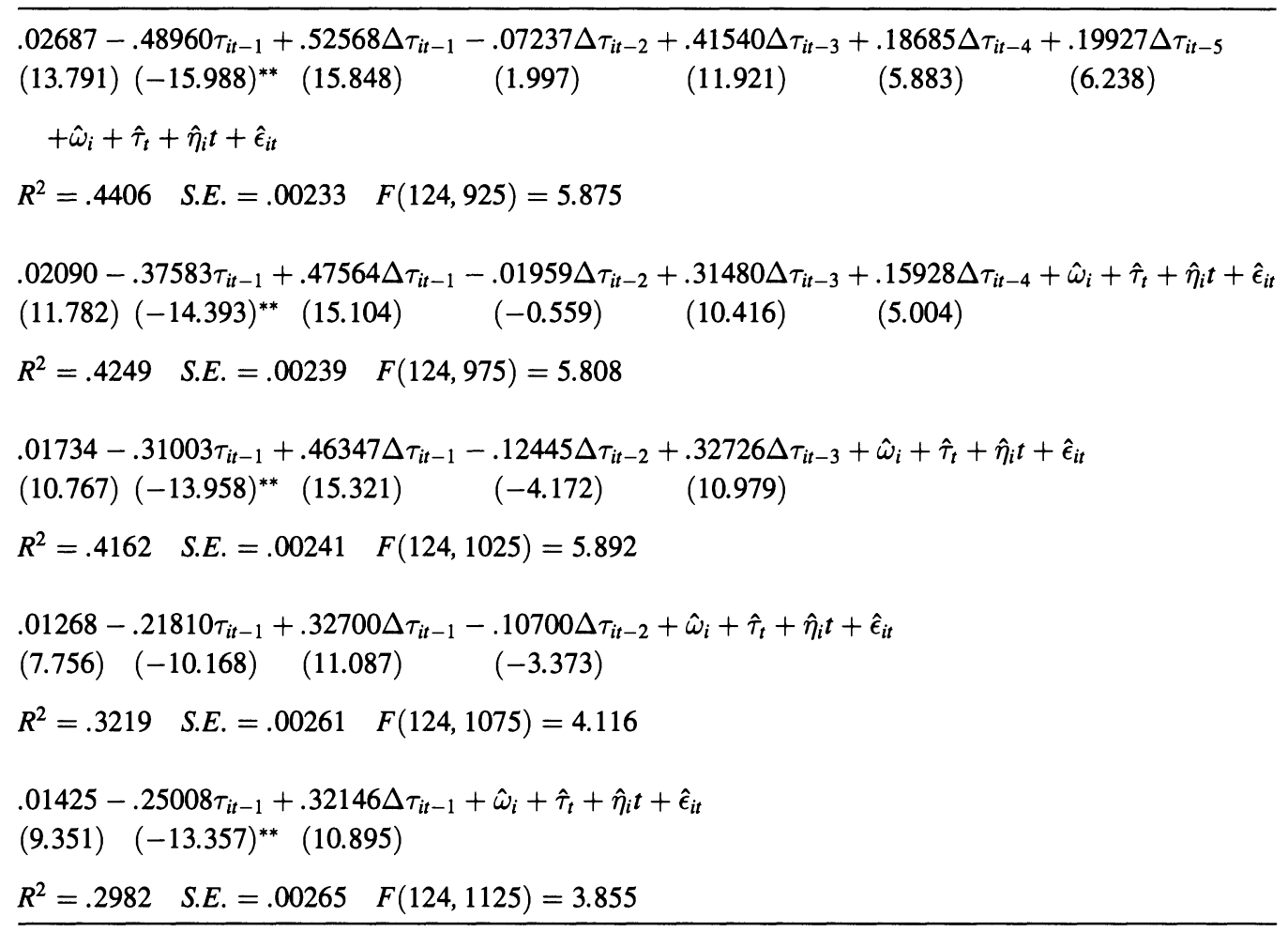

Notes: The dependent variable is $\Delta \tau_{i t}$. Unit root tests are shown with correction for serial correlation using the augmented Dickey and Fuller test with lags one through five. $t$-statistics are shown in parentheses. Critical values for the $t$-statistic of $\tau_{i t-1}$ are -10.35 and -10.89 at the $5 \%$ and $1 \%$ levels of significance respectively, and come from Table 5 in Levin and Lin for a sample size of $N=50$ and $T=25$.

**Significant at the $1 \%$ level. *Significant at the $5 \%$ level.

$$
\Delta \tau_{i t}=\omega_{i}+\eta_{i} t+\tau_{t}+\beta \tau_{i t-1}+\sum_{j=1}^{k} \theta_{j} \Delta \tau_{i t-j}+\varepsilon_{i t}
$$

$\tau_{i t}$ is the tax rate for state or province $i$ at time $t . \Delta$ is the first difference operator. $\beta$ is a parameter used to test the null hypothesis of a unit root. $\omega_{i}$ and $\eta_{i}$ are individual-specific fixed effects. $\omega_{i}$ is a state or province-specific intercept term equal to one for state or province $i$, and zero otherwise. $\eta_{i} t$ is a state or province-specific time trend, where $\eta_{i}$ is equal to one for state or province $i$, and zero otherwise. $\tau_{t}$ is a time-specific fixed effect equal to one at time $t$, and zero otherwise, and would allow for the possibility of a break in the series. $\theta_{j}$ is a parameter, and $k$ is the maximum number of lagged values of $\Delta \tau_{i t-j} . \sum_{j=1}^{k} \theta_{j} \Delta \tau_{i t-j}$ corrects for serial correlation in $\varepsilon_{i t}$ and is the panel data equivalent of the augmented Dickey and Fuller (ADF) test described in Said and Dickey [15]. $\varepsilon_{i t}$ is an error term that is independently and identically distributed across states or provinces and time, with zero mean and finite and nonzero variance, and is independent of $\omega_{i}$, $\eta_{i}$, and $\tau_{t}$. The test for a nonstationary $\tau_{i t}$ can be made by estimating equation (8), and checking the null hypothesis that $\beta=0$. The alternative hypothesis of stationarity would be $\beta<0$.

7. With a dependent variable of $\tau_{i t}$ in (8), the unit root null hypothesis would be $\beta=1$ and the alternative hypothesis would be $\beta<1$. 
Table II. Provincial Tax Rate Unit Root Tests in Panel Data: 1962-1989

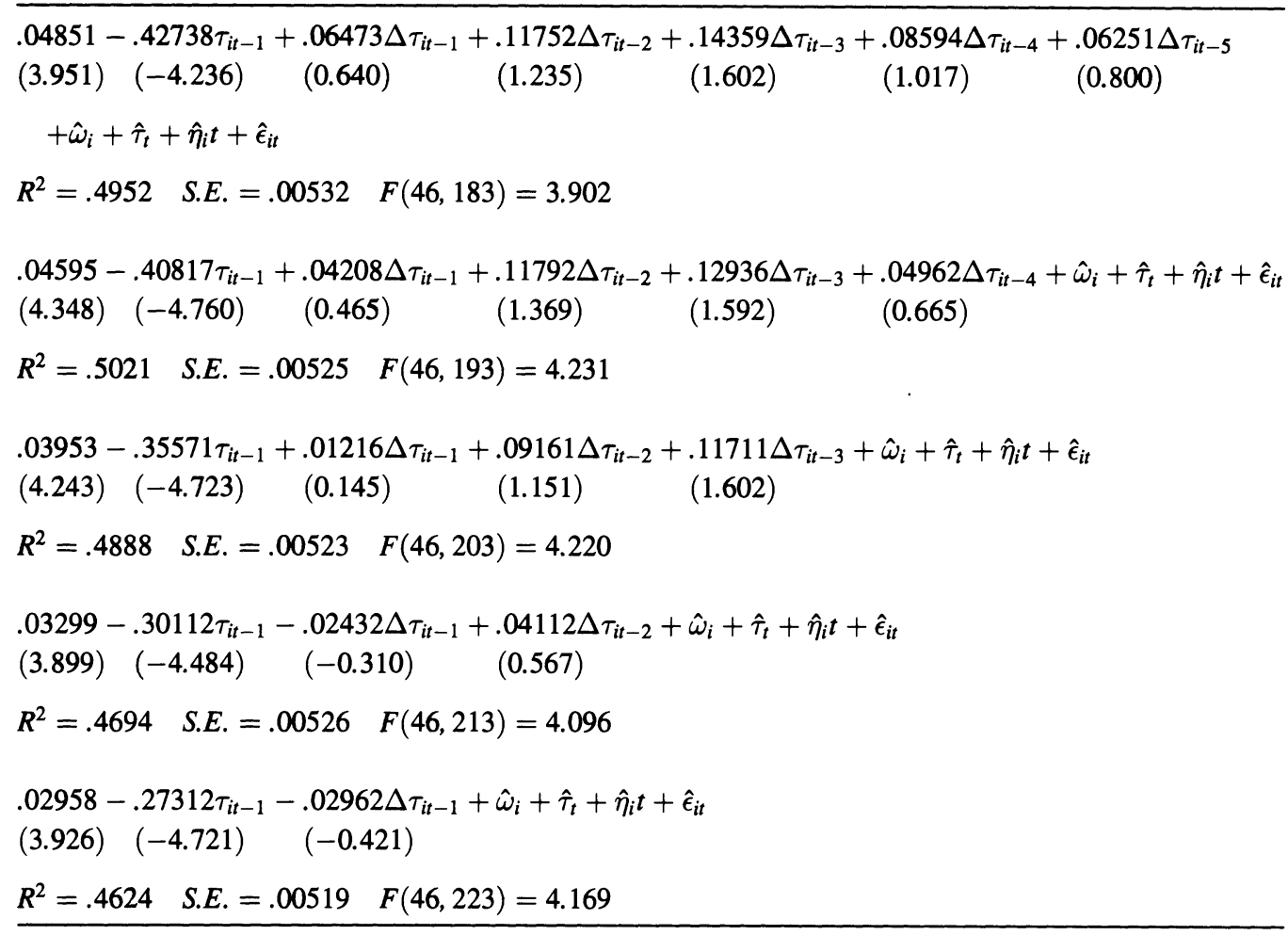

Notes: The dependent variable is $\Delta \tau_{i t}$. Unit root tests are shown with correction for serial correlation using the augmented Dickey and Fuller test with lags one through five. $t$-statistics are shown in parentheses. Critical values for the $t$-statistic of $\tau_{i t-1}$ are -5.42 and -5.94 at the $5 \%$ and $1 \%$ levels of significance respectively, and come from Table 5 in Levin and Lin for a sample size of $N=10$ and $T=25$.

**Significant at the $1 \%$ level. *Significant at the $5 \%$ level.

One advantage of using panel data, compared to a single time series, is the increased number of observations and greater degrees of freedom. Levin and Lin show that the power to reject the null hypothesis of a unit root, against a stationary alternative, increases significantly in panel data, and increases more rapidly with the number of time periods than with the number of individuals in the panel.

Unit root tests in panel data for the fifty states and ten provinces over the time periods 1963-89 and 1961-89 respectively, were performed as follows. ${ }^{8}$ Results are shown in Tables I and II.

State government results are shown in Table I. Correction for serially correlated disturbances is made by using the ADF test with one to five lags of $\Delta \tau_{i t-j}$. Critical values of the $t$-statistic testing the unit root null hypothesis $\beta=0$ are -10.35 and -10.89 , at the $5 \%$ and $1 \%$ levels of significance respectively. ${ }^{9}$ Except for the case of $j=2$ in the fourth ADF test, the null hypothesis of a unit root is clearly rejected for state governments. Four of the five $t$-statistics are much greater than their $1 \%$ critical values. ${ }^{10}$

8. The length of the state time series is limited by the availability of data on Gross State Product. The length of the provincial time series is limited by the lack of consistent data prior to 1961 .

9. Critical values come from Table 5 in Levin and Lin for sample size $N=50$ and $T=25$.

10. Four state governments have limited balanced budget rules. California, Connecticut, and New York require 
Provincial government results are shown in Table II. Critical values of the $t$-statistic testing the unit root null hypothesis $\beta=0$ are -5.42 and -5.94 , at the $5 \%$ and $1 \%$ levels of significance respectively. ${ }^{11}$ Contrary to the state government results, the null hypothesis of a unit root cannot be rejected for provincial governments in any case. Provincial government results support a random walk with drift for $\tau_{i t}$, where the drift varies by province and over time. Such a drift could occur if, for example, the marginal cost of tax collection differs by province and changes over time.

\section{Tests For Orthogonality}

The random walk implication of tax smoothing implies that changes in $\tau_{i t}$ are unpredictable from past information. Therefore, predictability of $\Delta \tau_{i t}$ rejects tax smoothing. It may also be the case that governments are not tax smoothing but that changes in spending and output, for example, cause $\tau_{i t}$ to behave as a random walk. Therefore, to further examine the random walk implication, and to test for evidence of an alternative hypothesis, regression of $\Delta \tau_{i t}$ on lagged values of $\Delta \tau_{i t}, \Delta g_{i t}$, and real output growth, $\Delta y_{i t}$, will be undertaken. ${ }^{12}$ Results of estimation are shown in Table III. ${ }^{13}$

State government results clearly reject the random walk implication of tax smoothing. All four lagged values of $\Delta \tau_{i t}$, two lagged values of $\Delta g_{i t}$, and three lagged values of $\Delta y_{i t}$, are significant at the usual levels, with all but $\Delta g_{i t-3}$ significant at the $1 \%$ level. Contrary to this, no lagged variables are significant in the provincial government tests, at the usual levels of significance. The above are in agreement with the unit root tests: tax smoothing is rejected for state governments but cannot be rejected for provincial governments. ${ }^{14}$

\section{Conclusion}

This study examined state and provincial government tax rates for evidence of tax smoothing. Results shown here reject tax smoothing by state governments but cannot reject tax smoothing by provincial governments.

only that the Governor submit a balanced budget, while Vermont has no explicit rules. All four of these states can carry over deficits. To see if these states should be excluded from the panel, unit root tests were undertaken with a panel of these four states alone. Results are similar to those shown above. The null hypothesis of a unit root is rejected in four of the five ADF tests undertaken, at the $1 \%$ level of significance. Therefore, all fifty states are included in the panel tested above. I thank an anonymous referee for suggesting that states without balanced budget rules be examined separately. Results are available from the author upon request.

11. Critical values come from Table 5 in Levin and Lin for sample size $N=10$ and $T=25$.

12. $\Delta y_{i t}$ was calculated as $\ln \left(y_{i t} / y_{i t-1}\right)$, where $y_{i}$ is real Gross State Product for state $i$, or real Gross Domestic Product for province $i$, respectively.

13. State or province-specific intercept terms were not significant, and were excluded from the results shown in Table III. Whether state or province-specific intercept terms were included or excluded did not affect the results shown in Table III.

14. As of 1987, Arkansas, Kentucky, Montana, Nevada, North Carolina, North Dakota, Oregon, and Texas had biennial budgets with biennial legislative cycles. As such, these states would appear to be limited to making only biennial tax rate changes. To see if inclusion or exclusion of these states makes a difference to the results, tests were undertaken excluding these states from the panel. Results are similar to the full sample results shown above. Tax smoothing is rejected at the same significance levels. Therefore, all fifty states are included in the tests shown above. Another reason for leaving these "biennial" states in the panel is that even these states sometimes make annual budget reviews. Results of testing are available from the author upon request. I thank an anonymous referee for suggesting that states with annual and biennial budgets be examined separately. 
Table III. State and Provincial Tests of Lagged Information

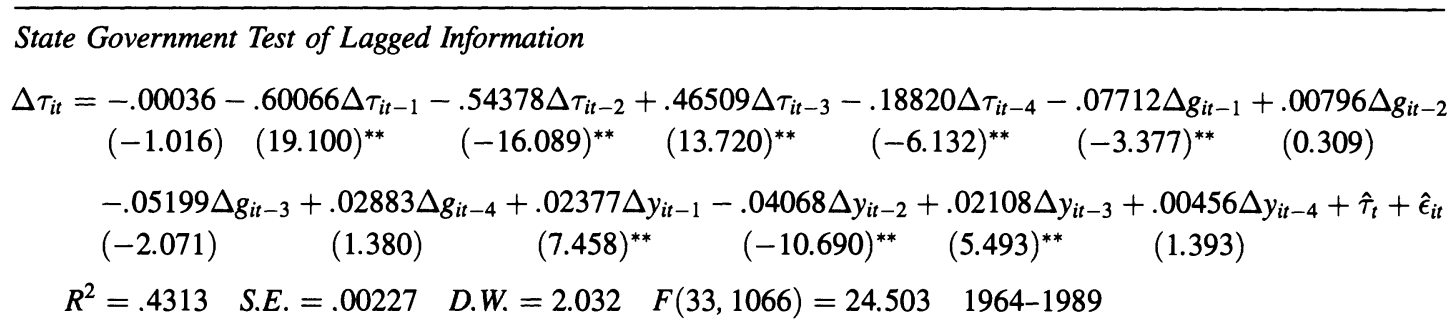

Provincial Government Test of Lagged Information

$$
\begin{aligned}
& \Delta \tau_{i t}=-.00367-.11698 \Delta \tau_{i t-1}+.03288 \Delta \tau_{i t-2}+.04499 \Delta \tau_{i t-3}-.05736 \Delta \tau_{i t-4}+.01759 \Delta g_{i t-1}+.00429 \Delta g_{i t-2} \\
& \begin{array}{llllll}
(-1.837) & (-1.532) & (0.424) & (0.566) & (-0.753) & (0.600)
\end{array} \\
& +.03805 \Delta g_{i t-3}-.00745 \Delta g_{i t-4}+.01082 \Delta y_{i t-1}+.01446 \Delta y_{i t-2}+.00782 \Delta y_{i t-3}-.01357 \Delta y_{i t-4}+\hat{\tau}_{t}+\hat{\epsilon}_{i t} \\
& \begin{array}{lllll}
(1.251) & (-0.271) & (0.844) & (1.156) & (0.635)
\end{array} \\
& R^{2}=.3839 \quad \text { S.E. }=.00568 \quad \text { D.W. }=2.037 \quad F(35,204)=3.632 \quad 1962-1989
\end{aligned}
$$

Notes: $\Delta \tau_{i t}$ and $\Delta g_{i t}$ are the first differenced tax rate and government spending to output ratios, and $\Delta y_{i t}$ is the growth of output, for state or province $i$ at time $t$, respectively. $\tau_{t}$ is a time-specific intercept term. $\epsilon_{i t}$ is the residual. $t$-statistics are shown in parentheses.

**Significant at the $1 \%$ level. *Significant at the $5 \%$ level.

Two types of tests were performed to examine the null hypothesis of tax smoothing. First, unit root tests were undertaken in panel data to directly test the random walk implication of tax smoothing. A unit root was rejected for U.S. state tax rates, but could not be rejected for Canadian provincial tax rates. Second, if governments are tax smoothing and tax rates behave as a random walk, then tax rate changes would be unpredictable from past information. The first differenced tax rate was regressed on lagged first differences of the tax rate, the ratio of government spending to output, and real output growth. Past information was found to be significant in predicting state tax rate changes, but not significant in predicting provincial tax rate changes.

Results suggest that state governments do not smooth tax rates, for example, by building up reserves in more prosperous times, but instead adjust spending and tax rates each year or two to balance their budgets. For state governments, business cycles result in changes in tax rates and spending that would be unnecessary if these governments were tax smoothing. Provincial government results support tax smoothing and contribute towards explaining the behavior of provincial government debt. Greater resource mobility between states than provinces was suggested as an explanation for the differences in tax 'smoothing.

\section{Data Appendix}

\section{United States}

Gross state product, by state: 1963-76, printed document; 1977-90, diskette, Bureau of Economic Analysis, U.S. Department of Commerce.

GNP deflator, U.S., (1982 = 100): 1929-90, National Income and Product Accounts, 1982 edition, and Survey of Current Business, various editions.

Real gross state product, by state: gross state product for each state divided by the U.S. GNP implicit price deflator $(1982=100)$, multiplied by one hundred. 
Tax revenue and government expenditures, by state: 1963-76, State Government Finances, annual publication; 1977-90, diskette, Bureau of the Census, U.S. Department of Commerce.

\section{Canada}

Gross domestic product, government expenditures, and tax revenue, by province: Statistics Canada, Provincial Economic Accounts, Annual Estimates, 1985-1989, 13-213, Ottawa, 1991; Provincial Economic Accounts, Historical Issue, 1961-1986, 13-213S, Ottawa, 1988. Tax revenue is total revenue minus nontax revenue. Nontax revenue includes "interest on loans, advances and investments" to crown corporations, "remittances from government business enterprises," "royalties" from natural resource ownership, "profits from liquor commissions," and transfers from the federal government. Quebec's tax revenue includes revenue from the Quebec pension plan.

GDP implicit price deflator, Canada $(1986=100): 1929-90$, Statistics Canada, Canadian Economic Observer, Historical Statistical Supplement 1990/91, 11-210, Ottawa, 1991.

Real gross domestic product, by province: gross domestic product for each province divided by the Canada GDP deflator $(1986=100)$, multiplied by one hundred.

\section{References} 940-71.

1. Barro, Robert J., “On the Determination of the Public Debt." Journal of Political Economy, October 1979,

2. - - "On the Predictability of Tax-Rate Changes." Working Paper, University of Rochester, October 1981.

3. - -U.S. Deficits Since World War I." Scandinavian Journal of Economics 88, 1986, 195-222.

4. Benjamin, Daniel K. and Levis A. Kochin. "A Theory of State and Local Government Debt." Working Paper, University of Washington, November 1978.

5. - "A Proposition on Windfalls and Taxes when Some but not All Resources Are Mobile." Economic Inquiry, July 1982, 393-404.

6. Bizer, David S. and Steven N. Durlauf, "Testing the Positive Theory of Government Finance." Journal of Monetary Economics, August 1990, 123-41.

7. —-, "Erratum." Journal of Monetary Economics, February 1991, 149.

8. Dickey, David A. and Wayne A. Fuller, "Distribution of the Estimators for Autoregressive Time Series with a Unit Root." Journal of the American Statistical Association, June 1979, 427-31.

9. Evans, Paul and Georgios Karras. "Are Government Activities Productive? Evidence from a Panel of U.S. States." Working Paper, The Ohio State University, December 1991.

10. Gupta, Kanhaya L., "Optimal Taxation Policy: Evidence from Canada." Public Finance 47, 1992, 193-200.

11. Huang, Chao-Hsi and Kenneth S. Lin, "Deficits, Government Expenditures, and Tax Smoothing in the United States: 1929-1988." Journal of Monetary Economics, June 1993, 317-39.

12. Horrigan, Brian R., "The Determinants of the Public Debt in the United States, 1953-1978." Economic Inquiry, January 1986, 11-23.

13. Kochin, Levis, Daniel Benjamin, and Mark Meador. "The Observational Equivalence of Rational and Irrational Consumers if Taxation Is Efficient," in West Coast Federal Reserve/Academic Conference 1985. San Francisco: Federal Reserve Bank of San Francisco, 1986.

14. Levin, Andrew and Chien-Fu Lin. "Unit Root Tests in Panel Data: Asymptotic and Finite-Sample Properties." Working Paper, University of California at San Diego, May 1992.

15. Said, Said E. and David A. Dickey, "Testing for Unit Roots in Autoregressive-Moving Average Models of Unknown Order." Biometrika 71, 1984, 599-604.

16. Sahasakul, Chaipat, "The U.S. Evidence on Optimal Taxation over Time." Journal of Monetary Economics, November 1986, 251-75.

17. Statistics Canada. Report on the Demographic Situation in Canada. Catalogue 91-209E. Ottawa, 1987.

18. Trehan, Bharat and Carl E. Walsh, "Common Trends, the Government's Budget Constraint, and Revenue Smoothing." Journal of Economic Dynamics and Control, June 1988, 425-44.

D.C., 1988, 1 .

19. U.S. Bureau of the Census. Geographical Mobility: March 1985 to March 1986. Series P-20, No. 425. Washington, 